Article

\title{
Bio-Degradable Polyurethane Foams Produced by Liquefied Polyol from Wheat Straw Biomass
}

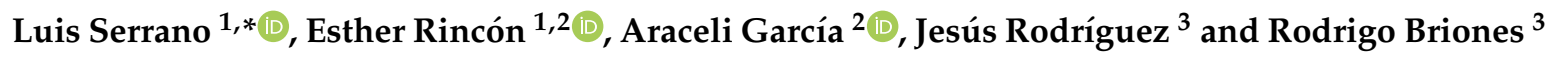 \\ 1 Inorganic Chemistry and Chemical Engineering Department, University of Cordoba, 14014 Cordoba, Spain; \\ b32rirue@uco.es \\ 2 Organic Chemistry Department, University of Cordoba, 14014 Cordoba, Spain; qo2ganua@uco.es \\ 3 Centro de Investigación de Polímeros Avanzados (CIPA), Av. Collao, Concepción 1202, Chile; \\ j.rodriguez@cipachile.cl (J.R.); r.briones@cipachile.cl (R.B.) \\ * Correspondence: luis.serrano@uco.es
}

Received: 20 October 2020; Accepted: 9 November 2020; Published: 10 November 2020

\begin{abstract}
In the present work, an abundant and unused residue (wheat straw) has been employed to synthesize a polyol as a substituent of castor oil in polyurethane foams. The liquefied product showed excellent properties for the proposed application. Castor oil was substituted with up to $50 \%$ wheat straw polyol in the formulation of polyurethane foams, which were prepared using two different isocyanates (methylene diphenyl diisocyanate (MDI) and toluene-2,4-diisocyanate (TDI)). The evaluation of physical, mechanical, and thermal properties of the foams revealed that these materials can successfully be formed with up to $40 \%$ wheat straw polyols since all the results were improved. Moreover, at this polyol concentration, the morphology of the foams was presented as a compact and ordered structure. Following this trend, the foams showed excellent biodegradability at 30 days (5.60 and $7.31 \%$ for TDI and MDI foams, respectively) and 60 days ( 8.49 and $9.88 \%$ for TDI and MDI foams, respectively) in the soil media tests carried out. Thus, the materials prepared in this work can be proposed for agricultural applications such as use in plant nurseries.
\end{abstract}

Keywords: wheat straw; liquefaction; foams; biodegradability

\section{Introduction}

The growing demand of the population on renewable energy sources, which overcome the dependence on fossil fuel resources, has led to many efforts to find the optimal source that meets expectations. In this regard, crop residues represent more than half of the agricultural biomass worldwide. Usually, these residues are discarded. Therefore, an efficient use of this biomass could solve the problems mentioned above [1].

Wheat is an agricultural crop with one of the highest production rates (734 million tons) and largest cultivation areas (214 million hectares) worldwide [2]. Therefore, it is also one of the major sources responsible for the generation of lignocellulosic agricultural biomass [3]. Specifically, if it is considered that $1 \mathrm{~kg}$ of grain produces $1 \mathrm{~kg}$ of straw (residue), an enormous amount of waste is generated each year [4]. Many efforts have been made in recent years to valorize this residue and these studies comprise a variety of applications such as bioethanol production [5], biocomposite obtention, food packaging materials acting as a polymer matrix [6,7], application as a binder in lithium batteries [8], and as part of polymer blends [9]. These successful examples of applications for wheat straw are very encouraging for the continuation of research towards new ways of exploitation.

In addition to these lignocellulosic biomass recovery strategies, there is another option known as liquefaction. That is, to carry out the complete conversion of the biomass into liquid fuels without the gasification step [10]. Thermochemical conversion mechanisms such as liquefaction allow the 
conversion of plant biomass into interesting products such as heat, power, electricity, chemicals, fuels, and other high-value materials. Traditionally, not much attention was paid to liquefaction as the requirements were complex and expensive, making it difficult to scale up industrial processes. However, advances in this field have made it possible to increase reaction yields by using organic solvents at atmospheric pressure and low temperature, thus obtaining the desired polymers and chemicals [11]. In particular, the liquefaction products that have been of most interest are bio-based adhesives and polyols. This is because they are compatible with conventional adhesives and resins such as epoxides, polyurethanes, and isocyanates, materials used in industries such as construction, automotive, pharmaceutical, etc., and which usually come from petroleum derivatives [11]. Of these, polyols are of particular importance since they are capable of being combined with isocyanates for the production of polyurethanes, used to produce flexible polyurethane foams, rigid polyurethane foams, coatings, adhesives, sealants, and elastomers [12].

Polyurethane foams are usually prepared by reacting an isocyanate compound and a polyhydroxylcontaining polymer. The latter is commonly derived from petrochemicals [13]. However, in order to partially or totally substitute these oil-based polyols, a wide variety of vegetable oils are being proposed, such as sunflower, castor, and soybean oils [14]. Castor oil is a very versatile vegetable oil due to its chemical composition, whose main component is 12-hydroxy-9-cis-octadenoic acid. This makes castor oil a good starting material for many applications since the hydroxyl functionality makes it very suitable for isocyanate reactions such as those mentioned above [15]. Unfortunately, castor oil has been classified as a semi-drying oil. This means that those materials incorporating castor oil in their structure will never achieve complete curing through oxidative crosslinking, as they would if they incorporated oils with many double bonds in each fatty acid moiety [16]. For this reason, castor oil substitution also needs to be addressed and biomass-derived polyols could represent a good alternative.

Herein, we report the preparation of wheat straw polyols through a liquefaction reaction, as well as its use for the preparation of biodegradable polyurethane foams by substituting castor oil. In addition, the influence of the structure of the isocyanate used during foam formulation is studied in order to elucidate the optimum composition for the prepared foams, addressing the maximum castor oil substitution. Therefore, biodegradability studies of the prepared foams have been developed for future applications in plant nurseries.

\section{Materials and Methods}

\subsection{Materials}

The wheat straw used in this study was provided by a local farmer in Cordoba, Spain. The raw material was conditioned up to constant moisture, ground in a hammer mill, sieved to obtain a 4-6 cm fraction free of impurities, and characterized according to standard methods [17]: 39.7\% cellulose; $30.6 \%$ hemicelluloses; $17.7 \%$ lignin; $7.7 \%$ ash, and $5.2 \%$ alcohol extractable. All determinations were performed by triplicate and the mean value was reported.

Reagents used during the liquefaction of wheat straw were glycerol (labkem, > 99\% purity), and $\mathrm{H}_{2} \mathrm{SO}_{4}$ (PanReac, 95\% purity, Barcelona, Spain). Employed reagents for the production of polyurethane foams were castor oil (Sigma Aldrich, St. Louis, MO, USA), dibutyltin dilaurate (Sigma Aldrich, 95\% purity, St. Louis, MO, USA), silicone oil (Sigma Aldrich, St. Louis, MO, USA), methane di-p-phenyl diisocyanate (Sigma Aldrich, 98\% purity, St. Louis, MO, USA), and toluene-2,4-diisocyanate (Sigma Aldrich, 80\% purity, St. Louis, MO, USA). All other reagents used in this study were of analytical grade.

\subsection{Liquefaction of wheat straw}

In a typical liquefaction procedure, $20 \mathrm{~g}$ of dried and milled wheat straw was loaded into a $500 \mathrm{~mL}$ glass reactor equipped with a mechanical stirrer, temperature control, and condenser. The raw material was mixed with $100 \mathrm{~mL}$ glycerol and $3 \mathrm{~g}$ of $\mathrm{H}_{2} \mathrm{SO}_{4}$ (catalyst) and heated until $160{ }^{\circ} \mathrm{C}$ for $1 \mathrm{~h}$ under 
constant stirring (300 rpm). These reaction conditions have been optimized by the research group in previous experiments $[18,19]$. After the residence time, the glass reactor was immersed in cold water to quench the reaction. The liquefied fraction was filtered to remove the un-reacted solid residue. The residue was washed with acetone several times, dried at $105{ }^{\circ} \mathrm{C}$ for $12 \mathrm{~h}$ in a ventilated oven, and weighed to determine the reaction yield $(\eta)$ as a measure of a liquefaction reaction extent:

$$
\eta=\left[1-\frac{M}{M_{0}}\right] \times 100
$$

where $M_{0}$ is the mass of initial dried wheat straw and $M$ is the mass of the final residue obtained after the liquefaction process.

\subsection{Preparation of Polyurethane Foams}

Polyurethane (PU) foams were synthesized in $370 \mathrm{~mL}$ plastic cups using the one-shot method. Polyol from wheat straw liquefaction (LWS) and castor oil were mixed into different proportions to evaluate the grade of substitution (bio-polyol vs. synthetic oil). The foaming formulation also included dibutyltin dilaurate as a catalyst, distilled water as a blowing agent, and silicone oil as a surfactant. The amounts of these components were kept constant to evaluate only the substitution possibility of castor oil by LWS. Finally, two different isocyanates, MDI (methylene diphenyl diisocyanate) and TDI (toluene-2,4-diisocyanate), were tested in the foam formulation (Table 1). It should be mentioned that the maximum grade of substitution achieved was $50 \%$, as it was not possible to obtain stable foams with higher substitution values.

Table 1. Foam formulations and nomenclature.

\begin{tabular}{ccccccccc}
\hline $\begin{array}{c}\text { Sample } \\
\text { Name }\end{array}$ & $\begin{array}{c}\text { Formulation } \\
\text { (CO: LWS) }\end{array}$ & CO (g) & LWS (g) & TDI (g) & MDI (g) & $\mathbf{R}_{\text {NCO/OH }}$ & Cream Time (s) & Free Rise Time (s) \\
\hline BT & Blank & 20 & 0 & 11.5 & 0 & 0.554 & 42 & 72 \\
80:20T & $80: 20$ & 16 & 4 & 11.5 & 0 & 0.647 & 50 & 98 \\
60:40T & $60: 40$ & 12 & 8 & 11.5 & 0 & 0.779 & 111 & 173 \\
50:50T & $50: 50$ & 10 & 10 & 11.5 & 0 & 0.867 & 102 & 148 \\
BM & Blank & 20 & 0 & 0 & 11.5 & 0.386 & 5.36 & 14.87 \\
80:20M & $80: 20$ & 16 & 4 & 0 & 11.5 & 0.451 & 7.43 & 25.96 \\
60:40M & $60: 40$ & 12 & 8 & 0 & 11.5 & 0.542 & 24.94 & 59.81 \\
50:50M & $50: 50$ & 10 & 10 & 0 & 11.5 & 0.603 & 51 & 72 \\
\hline
\end{tabular}

During the preparation, LWS, castor oil (CO), blowing agent (0.4 g), surfactant $(0.4 \mathrm{~g})$, and catalyst $(0.4 \mathrm{~g})$ were mixed for $1 \mathrm{~min}$ at $1000 \mathrm{rpm}$ using mechanical stirring. Isocyanate was then added and remained under stirring for $20 \mathrm{~s}$ at $1000 \mathrm{rpm}$. Finally, the contents of the plastic cups were allowed to foam and settle for a week prior to analysis.

During the foam production some physical properties were measured (Table 1). Cream time is the time in seconds where the mixture begins to change from liquid to a creamy state before expansion. Free rise time is the time in seconds from the expansion starting point to the maximum height of the foam [20].

The $\mathrm{NCO} / \mathrm{OH}$ molar ratio $\left(\mathrm{R}_{\mathrm{NCO} / \mathrm{OH}}\right)$ was calculated following the method described by Kim et al. [21] as reported in a previous study [22]:

$$
\mathrm{R}_{\mathrm{NCO} / \mathrm{OH}}=\frac{\frac{\text { Isocyanate }(g) \times 2}{M W_{\text {Isocyanate }}}}{\frac{\mathrm{H}_{2} \mathrm{O}(\mathrm{g}) \times 2}{M W_{\mathrm{H}_{2} \mathrm{O}}}+\frac{L W S(g) \times 33.56}{M W_{L W S}}+\frac{C O(g) \times 9.06}{M W_{\mathrm{CO}}}}
$$




\subsection{Characterization of Products}

\subsubsection{Liquefied Product}

The $\mathrm{pH}$ was measured using $1 \mathrm{~g}$ of liquefied product dissolved in $50 \mathrm{~mL}$ of water. The mixture was vigorously stirred, and the $\mathrm{pH}$ was recorded in triplicate using a calibrated $\mathrm{pH}$ meter (Crison GLP 31, Barcelona, Spain).

Viscosity measurements were carried out at $20^{\circ} \mathrm{C}$ using a rotatory viscometer (Selecta ST-2020, La Rioja, Spain).

The molecular weight distribution of LWS was determined by size-exclusion chromatography (SEC) in a PL-GPC 50 integrated gel permeation chromatography (GPC) system (Agilent Technologies, Madrid, Spain) at $50{ }^{\circ} \mathrm{C}$, equipped with a refractive index (RI) detector, a KD-G 4A guard column (Shodex, Prague, Czech Republic), and a KD-806 M column (Shodex).

The hydroxyl number $\left(\mathrm{I}_{\mathrm{OH}}\right)$ was determined following the American Society for Testing and Materials (ASTM) D4274-16 standard [23]. It consisted of dissolving a weighed amount of liquefied product in an acetylation reagent (acetic anhydride in pyridine) and the mixture was heated in a water bath at $98^{\circ} \mathrm{C}$ for $2 \mathrm{~h}$. The acetic acid formed was titrated with $0.5 \mathrm{~N} \mathrm{NaOH}$ solution. The $\mathrm{I}_{\mathrm{OH}}$ was corrected using the acid number due to the acid character of LWS. LWS was dissolved in a $50 \mathrm{~mL}$ mixture of dioxane and water $(4: 1 \mathrm{v} / \mathrm{v})$, phenolphthalein $(1 \%$ ethanol) was added, and the solution was titrated with $0.1 \mathrm{M} \mathrm{KOH}$. Both the $\mathrm{I}_{\mathrm{OH}}$ and acid number of the samples were obtained by the difference in titration between the blank and the sample solutions. All the determinations were repeated in triplicate and standard deviation is shown.

\subsubsection{LWS-Formulated PU Foams}

The densities of the foam samples were determined according to ASTM D1622-14 [24]. The compressive strength was determined in general accordance with ASTM D1621-16 [25], on a universal testing machine (Instron Tecsis 4468) with a load cell of $50 \mathrm{kN}$ at the cross-head speed of $2.5 \mathrm{~mm} / \mathrm{min}$. The load was parallel to the foam rise direction. The specimens were those used in the apparent density measurement. The compressive strength was the stress at the yield point (if before $10 \%$ deformation) or the stress at $10 \%$ deformation. The reported results are averages of at least three samples [26].

Scanning electronic microscopy (SEM) was carried out on the obtained foams to observe and evaluate the cell morphology of the foams. The imaging was performed with a JEOL JSM-6300 scanning microscope equipment operated at $20 \mathrm{kV}$ and beam currents between 0.01 and $0.1 \mathrm{nA}$. The cell size of the prepared foams was measured using ImageJ.

Thermal properties of PU foams were analyzed using a TA Instrument TGA Q50 thermogravimetric analyzer (Mettler-Toledo, Barcelona, Spain). The measurements of samples' weight loss in relation to the temperature of thermal degradation were carried out between 50 and $800^{\circ} \mathrm{C}$ at $10^{\circ} \mathrm{C} / \mathrm{min}$ under a $\mathrm{N}_{2}$ flow $(20 \mathrm{~mL} / \mathrm{min})$.

The determination of the biodegradability of PU foams was conducted according to ASTM D5988-03 [27]. The soil medium used for the test was leaf soil from the nursery of the University of Bío bío, with a humidity of $62 \%$. The foams were cut to an area of $1 \mathrm{~cm}^{2}$ and weighed $\left(W_{i}\right)$. Each foam was then buried $2 \mathrm{~cm}$ deep in a polypropylene plastic capsule, where the substrate was located. After 30 and 60 days, the foams were dug up, washed with distilled water, dried in an oven at $50{ }^{\circ} \mathrm{C}$ for $24 \mathrm{~h}$ and weighed $\left(W_{f}\right)$. The percentage of biodegradability $(\% D)$ was calculated as the difference between the initial and final weights of the samples according to the following equation:

$$
\% D=\frac{W_{i}-W_{f}}{W_{i}} \times 100
$$




\section{Results and Discussion}

\subsection{Chemical Composition of Wheat Straw}

The chemical composition of wheat straw with $39.7 \%$ cellulose and $30.6 \%$ hemicelluloses ensures a high availability of hydroxyl groups, being a carbon and hydrogen rich feedstock, apt for success in the liquefaction reaction process. Previous studies of the research group, using a great variety of agricultural residues with similar composition, gave us enough experience to carry out the wheat straw liquefaction.

The high ash content $(7.7 \%)$ was lower than other similar straws such as rice straw $(15.2 \%)$ or corn straw (12.4\%) [18], but it could cause some yield problems during the liquefaction reaction.

\subsection{Wheat Straw Liquefaction and Product Properties}

The liquefaction reaction carried out for wheat straw enabled a high yield to be obtained, which was close to the maximum (Table 2). This suggested that, as expected, the large amount of hydroxyl groups (from cellulose and hemicelluloses) ensured the success of the reaction. During the liquefaction process, two reactions occur. When the first one (degradation) predominates, the greatest decomposition of the raw material takes place and, therefore, the amount of unconverted material is reduced, thus increasing the yield. However, when the second reaction (repolymerization) predominates, the solid residue content increases. In the case of LWS, it seems that the first reaction predominated, which is why such high yields were obtained. This result is due to the chosen reaction conditions optimized by the research group in previous research $[18,19]$.

Table 2. Wheat straw polyol properties.

\begin{tabular}{cccccccc}
\hline Sample & Yield (\%) & pH $\left(\mathbf{2 5}{ }^{\circ} \mathbf{C}\right)$ & $\begin{array}{c}\mathbf{I}_{\mathrm{OH}} \\
(\mathbf{m g ~ K O H} / \mathbf{g})\end{array}$ & $\begin{array}{c}\text { Acid number } \\
(\mathbf{m g ~ K O H} / \mathbf{g})\end{array}$ & $\begin{array}{c}\text { Viscosity } \\
(\mathbf{P a} \cdot \mathbf{s})\end{array}$ & $\begin{array}{c}\mathbf{M w} \\
(\mathrm{g} / \mathbf{m o l})\end{array}$ & $\begin{array}{c}\mathbf{M n} \\
(\mathrm{g} / \mathbf{m o l})\end{array}$ \\
\hline LWS & 96.5 & $1.63 \pm 0.02$ & $604.1 \pm 9.1$ & $59.2 \pm 0.86$ & $0.6 \pm 0.05$ & 30,463 & 28,170 \\
\hline
\end{tabular}

Considering the proposed application for LWS (PU foam preparation), the hydroxyl number, viscosity, and molecular weight are the most important parameters to consider. LWS exhibited a hydroxyl number of $604.1 \mathrm{mg} \mathrm{KOH} / \mathrm{g}$. Polyols from petrochemical origin, usually employed in industry, present a hydroxyl number of about $200 \mathrm{mg} / \mathrm{g}$ [28]. Polyols from natural oils studied in the literature present slightly higher hydroxyl number values. For example, Kurańska and Prociak [28] reported $276 \mathrm{mg} \mathrm{KOH} / \mathrm{g}$ for rapeseed-oil-based polyol. Similarly, Zlatanić et al. [29] reported 207.0, 231.4, and $237.1 \mathrm{mg} \mathrm{KOH} / \mathrm{g}$ for canola, soybean, and sunflower-oil-based polyols, respectively. When it comes to castor oil, it has a higher value $(408 \mathrm{mg} \mathrm{KOH} / \mathrm{g})$ with similar liquefaction yields (92.54\%) [15]. In these cases, a low hydroxyl number was related to high viscosity since viscosity values were 2.94, 3.35, and 4.08 Pa.s for canola, soybean, and sunflower-oil-based polyols [29]. Castor-oil-based polyol, with a high hydroxyl number, exhibited $16.4 \mathrm{~Pa} \cdot \mathrm{s}$ [15]. These oils were all successfully used for the preparation of polyurethane foams, with castor oil being the one that provided the best foams. These findings suggest that a high hydroxyl number, such as that obtained for LWS, is very desirable for the preparation of polyurethane foams.

\subsection{LWS-PU Foam Properties}

The as-obtained LWS was used to prepare polyurethane foams as a substitute for castor oil, also studying the influence of the isocyanate used in the process. To this end, two different isocyanates were tested: TDI and MDI. These isocyanates, usually used in industry, have different structures that can influence the process of foam formation. Thus, TDI, with an aromatic ring, presents an asymmetry that disturbs the structure of the hard segment. This event is not found in MDI, which has two aromatic rings since it does not present the same isometric asymmetry [22]. 
With both isocyanates, it was possible to replace the castor oil up to a maximum of $50 \%$. Foams formulated with TDI exhibited $\mathrm{R}_{\mathrm{NCO} / \mathrm{OH}}$ from 0.554 to 0.867 . In the case of MDI, as expected due to its higher molecular weight, the range was slightly lower since the blank sample (BM) exhibited $\mathrm{R}_{\mathrm{NCO} / \mathrm{OH}}$ of 0.386 and the $50: 50 \mathrm{M}$ foam $\mathrm{R}_{\mathrm{NCO} / \mathrm{OH}}$ of 0.603 . If cream and free rise times are considered (Table 1), these both increased with a greater amount of polyol in the structure. This is because more polyol in the system requires more time to start the gelling and blowing reactions. Again, differences in cream and free rise times between TDI- and MDI-formulated foams were observed, with the latter being considerably shorter. In other words, lower $\mathrm{R}_{\mathrm{NCO} / \mathrm{OH}}$ meant lower cream and free rise times. This event was described by Zhang et al. [30] for polyurethane foams prepared with oilseed rape straw, rice straw, wheat straw, and corn stover, where the higher the $\mathrm{R}_{\mathrm{NCO} / \mathrm{OH}}$, the shorter the foaming times.

Apparent densities of the TDI- and MDI-LWS foams are displayed in Figure 1. In the case of the TDI foams, the blank sample (BT) presented a very high apparent density value $\left(370.1 \mathrm{Kg} / \mathrm{m}^{3}\right.$, Table S1). We have previously reported that this effect is due to a shorter cure rate than gas formation rate, which promotes a collapse of the foam before curing [22]. For this reason, we consider that the data obtained from this sample should not be used, since the sample obtained was as hard as a stone, instead of the consistency of a foam. The rest of the foams formulated with TDI presented apparent densities in the range $30-105 \mathrm{Kg} / \mathrm{m}^{3}$. When LWS was present in the foam at 20 and $40 \%$, the densities were very similar $\left(\mathrm{R}_{\mathrm{NCO} / \mathrm{OH}}\right.$ of 0.647 and 0.779 , respectively). However, as the amount of polyol in the system increased to $50 \%$, the density more than doubled $\left(103.0 \mathrm{Kg} / \mathrm{m}^{3}\right.$, Table S1). Foams $80: 20 \mathrm{~T}$ and 60:40T exhibited density values similar to those foams prepared with oilseed rape straw and rice straw [30]. However, these foams were prepared with a $\mathrm{R}_{\mathrm{NCO} / \mathrm{OH}}$ considerably higher (1.0) than those reported in the present study. Similarly, castor-oil-based PU foams presented density values between $36.0-36.8 \mathrm{Kg} / \mathrm{m}^{3}$ [15]. This means that to obtain the same density value, the presence of LWS replacing castor oil achieves the same result but with a significantly lower $\mathrm{R}_{\mathrm{CNO} / \mathrm{OH}}$.

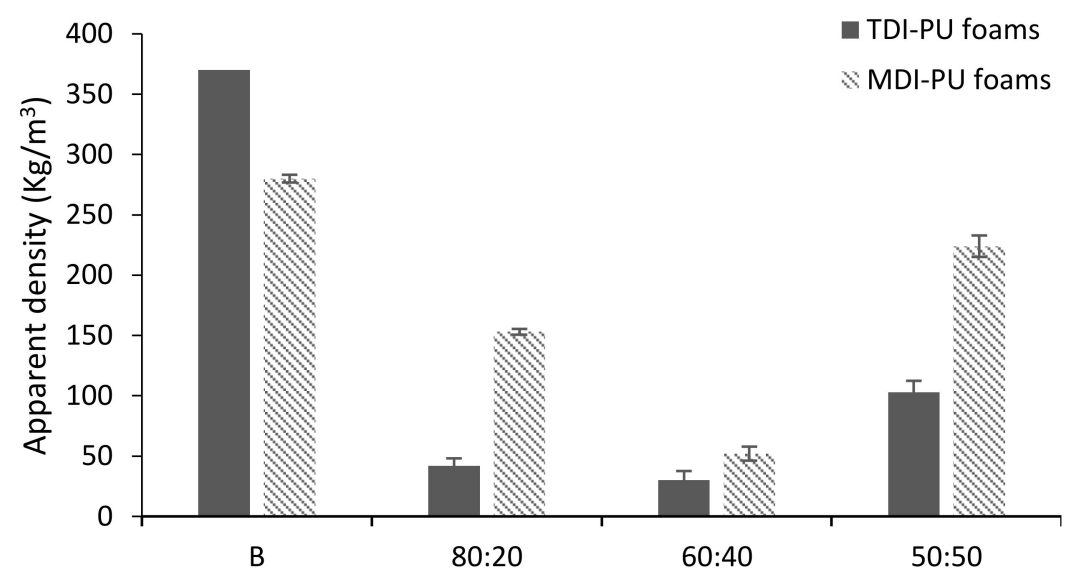

Figure 1. Apparent density of wheat straw liquefaction (LWS)-formulated polyurethane (PU) foams.

On the other hand, in general, the foams prepared with MDI showed much higher apparent density values (in the range $50-280 \mathrm{Kg} / \mathrm{m}^{3}$ ) with $\mathrm{R}_{\mathrm{NCO} / \mathrm{OH}}$ slightly lower than the TDI foams. However, MDI foams did not exhibit the slightly upward trend in density with the amount of polyol in the system that was observed in TDI foams. In this case, the density decreased from the blank sample to 60:40 foam, then increased slightly to 50\% LWS in the system. This same trend has been reported for PU foams formulated with epoxidized rapeseed oil, where by increasing the amount of polyol in the material, the described density fluctuation was observed [31].

Mechanical properties results are shown in Figure 2. In the case of TDI foams, they showed increasing compression strength values as the amount of LWS in the foam increased, up to $40 \%$ substitution (from $3.2 \mathrm{KPa}$ in $\mathrm{BT}$ to $11.7 \mathrm{KPa}$ in $60: 40 \mathrm{~T}$ ). As the LWS in the system increased to $50 \%$, the compression strength decreased to $5 \mathrm{KPa}$ (Table S1). 


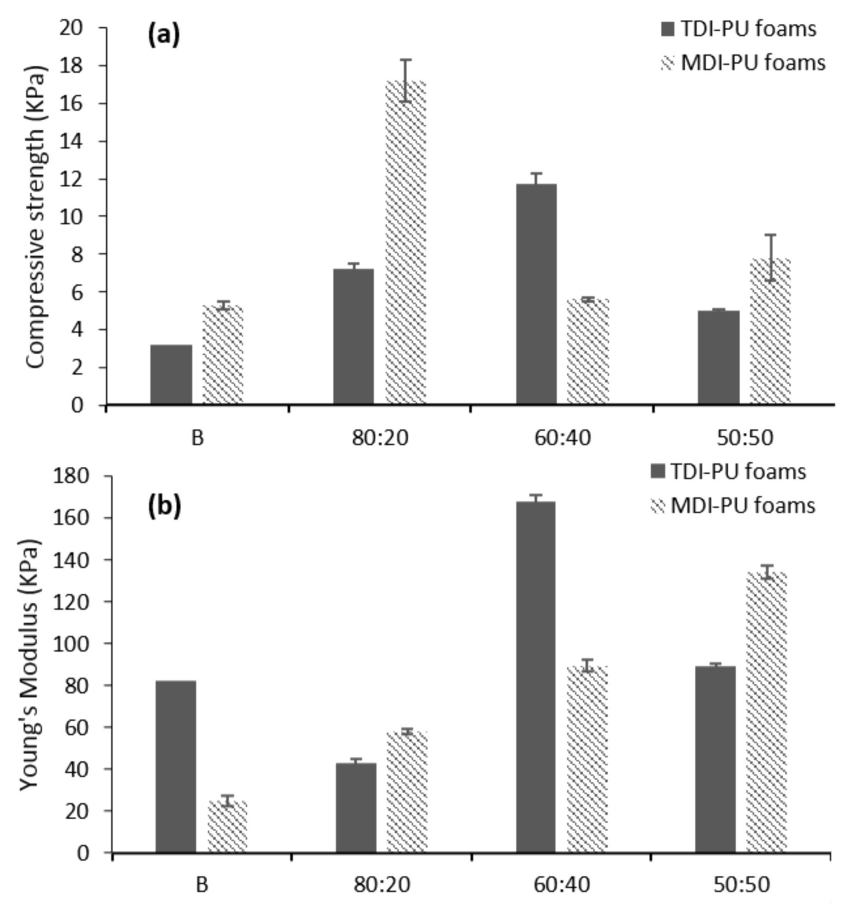

Figure 2. Mechanical properties of LWS-formulated PU foams: (a) Compressive strength and (b) Young's Modulus.

MDI foams again showed a fluctuating trend where the compression strength increased for the 80:20M sample $(17.2 \mathrm{KPa})$ with respect to $\mathrm{BM}(5.3 \mathrm{KPa})$, then decreased considerably with $40 \%$ LWS and increased again slightly for 50:50M foam $(7.8 \mathrm{KPa})$. The compressive strength values obtained confirmed that the prepared foams were of a flexible type, which is usually classified according to the mechanical performance. Flexible PU foams owe their properties to phase separation: hard segment and soft segment. The hard segment would be the zone that physically intercrosses, giving firmness to the polymer, while the soft segment is made up of stretchable chains that give the polymer elasticity [32].

Regarding the Young's modulus, the 80:20T sample was the one exhibiting the best result with 167.5 KPa. From then on, the value started to decrease presenting 89.3 KPa for 50:50T sample. In contrast, the foams formulated with MDI presented higher Young's moduli as the amount of LWS increased (from 24.9 KPa in BM to 134.2 KPa in 50:50M). If these data are compared with those of flexible foams prepared with castor oil, it can be observed that, both using TDI and MDI, the values obtained in the present work increase more than ten times from those described in the literature [33].

As apparent density values vary between the foam samples, mechanical properties were calculated avoiding the effect of the density. In this way, specific mechanical properties were obtained and are displayed in Figure 3. As observed, 60:40T is still the TDI foam with the best result, both in compressive strength and Young's modulus. Interestingly, this calculation helped to determine which MDI foam was the optimal. At equal compressive strength, the Young's modulus was considerably higher for the 60:40M sample.

Considering the results obtained in the evaluation of apparent density and mechanical properties, it could be stated that castor oil can be replaced by LWS up to $40 \%$, maintaining its properties, regardless of the isocyanate used.

The morphology of the cells in the prepared foams was studied by SEM. As mentioned above, the high hardness of the blank sample prepared with TDI (BT) made this analysis impossible for that sample. The SEM images of the other LWS-TDI-formulated foams are shown in Figure 4. When LWS was present at 20\% (80:20T), the cell morphology was found to be amorphous, as cell diameters from 0.38 to $0.84 \mathrm{~mm}$ were present. When the presence of LWS was increased to $40 \%(60: 40 \mathrm{~T})$, the structure found was very uniform and ordered, with an average cell diameter of $0.56 \pm 0.11 \mathrm{~mm}$. When the 
maximum degree of castor oil substitution was reached (50:50T), the cell structure reappeared as disordered and with very variable sizes from $0.50 \mathrm{~mm}$ to $1.89 \mathrm{~mm}$. This fact has been previously described by other authors, who claim that the difference in cell morphology when the amount of polyol increases is due to the increase in viscosity [30]. As the size of the cell increases, holes appear in the structure causing lower performance of these foams. In addition, the increase in $\mathrm{R}_{\mathrm{NCO} / \mathrm{OH}}$ (0.779 and 0.867 for 60:40T and 50:50T, respectively) slows the release of $\mathrm{CO}_{2}$ during the formation of the foams, forming a compact layer and causing the concentrated gas to break through the cell wall and form holes [22]. In addition, if the morphology obtained is contrasted with the mechanical properties previously evaluated, it can be observed that there is a perfect correlation. The foam formulated with TDI that presented the best mechanical performance (60:40T), was the same one that exhibited an orderly and compact cell morphology.
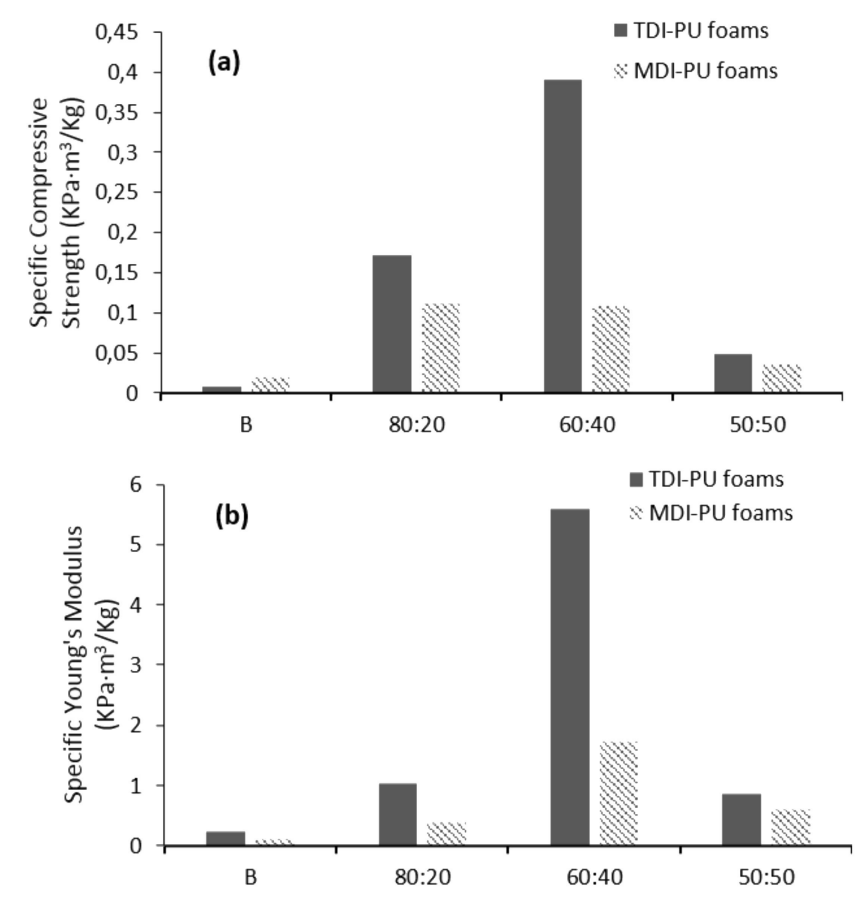

Figure 3. Specific (a) compressive strength and (b) Young's Modulus of LWS-formulated PU foams.

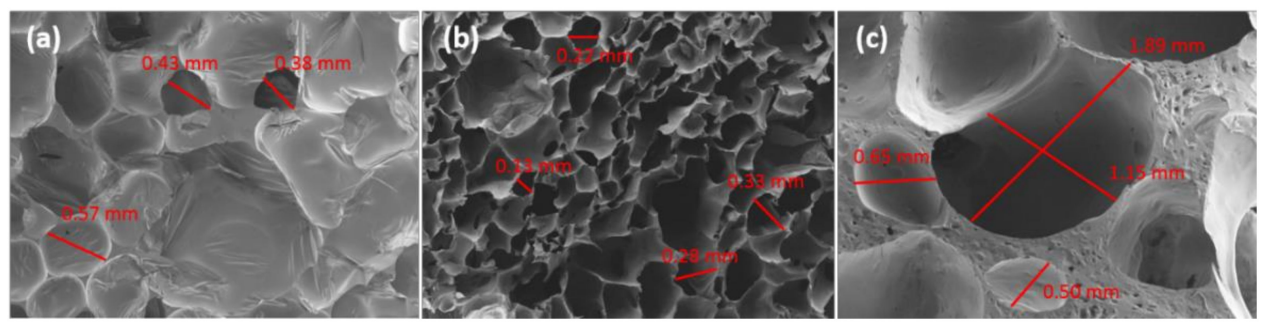

Figure 4. SEM images of (a) 80:20T, (b) 60:40T, and (c) 50:50T foams.

SEM micrographs of LWS-MDI-formulated foams are shown in Figure 5. As with the foams formulated with TDI, MDI-formulated foams showed an ordered cell structure for $80: 20 \mathrm{M}$ and $60: 40 \mathrm{M}$ formulations (cell diameter of $0.28 \pm 0.04 \mathrm{~mm}$ in both cases). These, in turn, had the best mechanical properties. When dealing with foams prepared with vegetable oils, the cells are usually arranged and reduced in size as the amount of bio-polyol in the structure increases, as reported by Tu et al. [34] for PU foams prepared with soybean-oil-based polyol. 

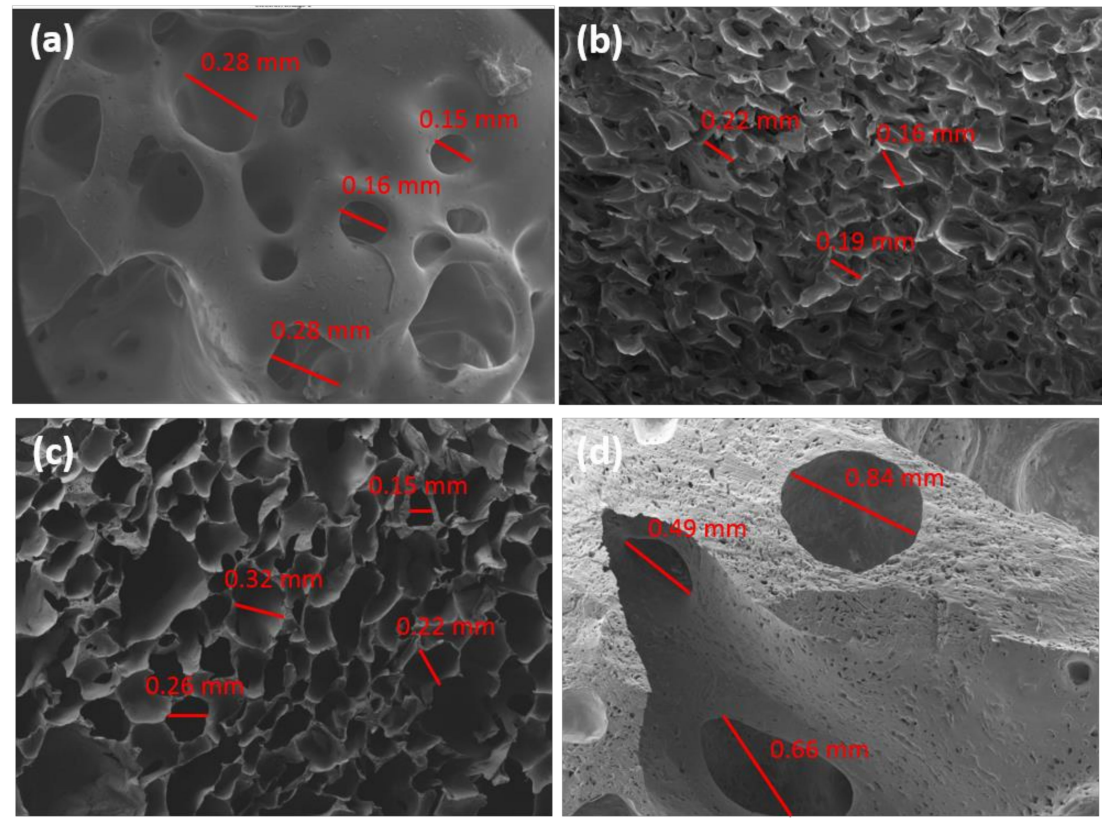

Figure 5. SEM images of (a) BM, (b) 80:20M, (c) 60:40M, and (d) 50:50M foams.

The foams formulated with castor oil that have been evaluated in the literature show a very similar morphology to those presented in this work, with cell diameters between 0.12 and $0.5 \mathrm{~mm}$. Therefore, the data obtained suggest that LWS could be a very suitable candidate to replace castor oil in the formulation of PU foams [35].

Finally, prior to the application proposed for the LWS-formulated foams, the thermal properties were evaluated by TGA. Thus, the TGA and derivative thermogravimetric (DTG) curves of the TDI foams are shown in Figure 6.
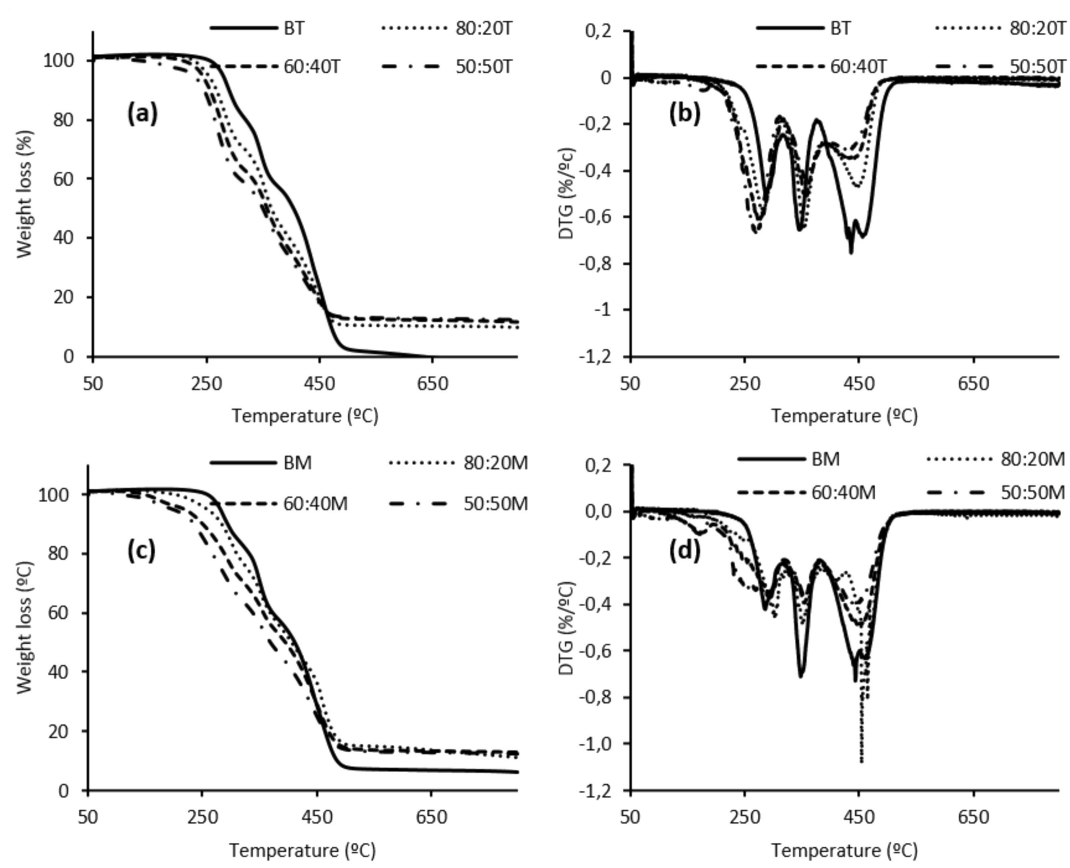

Figure 6. (a)TGA and (b) DTG curves of foams prepared with TDI. (c) TGA and (d) DTG curves of foams formulated with MDI. 
As explained in a previous work on PU foams with a laurel tree pruning waste-based polyol, the degradation mechanism of PU foams is complicated. Many degradation products are formed resulting in differential weight loss curves with many peaks [22].

Thus, TDI foams showed three main decomposition peaks $\left(T_{1}, T_{2}\right.$, and $T_{3}$ in Table $\left.S 2\right)$. The first peak of degradation, associated with the loss of volatile compounds, is between $264-289^{\circ} \mathrm{C}$. The $\mathrm{T}_{2}$ peak, attributed to the breakdown of the urethane links of the polymer, is the range $354-356^{\circ} \mathrm{C}$. The last peak of degradation, $\mathrm{T}_{3}$, due to the decomposition of LWS, is in the range $436-447^{\circ} \mathrm{C}$. The very weak variation in temperature ranges of the decomposition peaks was not significant between the different TDI-LWS foams. However, it should be noted that the first stage of decomposition is quite significant between LWS foams and the reference foam (BT). Thus, the blank sample remains without weight loss until $257^{\circ} \mathrm{C}$, while foams incorporating $20 \%$ LWS begin to lose weight at $228^{\circ} \mathrm{C}$, an event that intensifies as the amount of LWS in the system increases (50:50T sample begins to lose weight at $208^{\circ} \mathrm{C}$ ). Therefore, it could be said that, despite having a slightly lower resistance to thermal degradation than the blank, TDI foams have good thermal characters since they remain stable up to $200{ }^{\circ} \mathrm{C}$.

TGA and DTG curves of LWS-MDI foams are also presented in Figure 6. In this case, again three main degradation peaks were found (Table S2). The ranges of the three peaks were slightly higher than for the foams formulated with TDI $\left(297-302{ }^{\circ} \mathrm{C}, 348-353{ }^{\circ} \mathrm{C}\right.$, and $447-457{ }^{\circ} \mathrm{C}$ for $\mathrm{T}_{1}, \mathrm{~T}_{2}$, and $\mathrm{T}_{3}$, respectively). This was an indication that the foams formulated with MDI had a slightly higher resistance to thermal degradation than TDI. This may be because $\mathrm{R}_{\mathrm{NCO} / \mathrm{OH}}$ of these foams was lower than that of the TDI foams. Although this decreased $\mathrm{R}_{\mathrm{NCO} / \mathrm{OH}}$ indicates that fewer urethane bonds will be formed in MDI foams, the structural differences between these two diisocyanates should be considered. It seems that the presence of two aromatic rings in MDI, rather than one as in TDI, in addition to the lack of isometric asymmetry of this compound, promotes the slower thermal degradation in MDI foams. Castor-oil-formulated foams in the literature also show the three typical degradation peaks. However, the temperatures of these events are lower $\left(223.7,324.0\right.$, and $487.5^{\circ} \mathrm{C}$, for $T_{1}, T_{2}$, and $T_{3}$, respectively). This indicates that $L W S$ is able to successfully replace castor oil in PU foams by not only maintaining but also improving the properties of the foams [36].

\subsection{LWS-PU Foam Application: Biodegradability in Soil Media}

PU foams of petrochemical origin are non-biodegradable materials. Therefore, the development of PU foams that incorporate bio-polyols such as LWS should not only match or improve the mechanical properties or morphology of the former but should also be biodegradable. This is how the possible replacement of PU by active polyols derived from natural resources could be stated. In this sense, the foams prepared in this work were subjected to biodegradability tests over $30\left(\% D_{30}\right)$ and 60 days $\left(\% D_{60}\right)$, obtaining the results shown in Figure 7.

In the case of TDI-formulated foams, it was observed that the biodegradability, both at 30 and 60 days, was very similar in the case of $80: 20 \mathrm{~T}$ (5.09 and $8.48 \%$ of $\% D_{30}$ and $\% D_{60}$, respectively) and 60:40T (5.60 and $8.49 \%$ of $\% D_{30}$ and $\% D_{60}$, respectively) foams (Table S2). The most remarkable increase in biodegradability was the 50:50T foam that presented $8.57 \%$ at 30 days and $12.25 \%$ at 60 days. MDI-formulated foams exhibited a moderate increasing trend with increasing LWS substitution for $\% D_{30}$. Thus, $60: 40 \mathrm{M}$ foam exhibited $7.31 \%$ biodegradability, an increased property compared to the blank sample (BM $0.23 \%$ ) and the $80: 20 \mathrm{M}$ foam (2.08\%). From 40\% LWS in the material, the biodegradability at 30 days was maintained, despite increasing the amount of polyol in the system (7.21\% for 50:50M). When biodegradability at 60 days was studied for these same foams, it was found that this property was directly related to the amount of LWS. Thus, the most substituted foam (50:50M) presented $11.28 \%$, a much higher result than the blank (3.18\%).

If the results obtained in this study are compared with foams formulated with vegetable oils, it can be stated that LWS significantly improved the biodegradability of the polymers. The foams with soybean oil showed less than $7.5 \%$ biodegradability after 100 days of testing. The same applies to foams formulated with castor oil that exhibit less than 5\% biodegradability after 100 days [37]. 
Foams formulated entirely with castor oil usually have such low biodegradability due to their hydrophobic nature (long chains of aliphatic acidic hydrocarbons). Therefore, water molecules cannot penetrate the matrix and reach the hydrolytically labile ester groups of the castor oil. In our case, as the amount of LWS replacing castor oil increases, the biodegradability of the material increases. A possible explanation for this is the increase of more polyethylene glycol (PEG) segments from the polyol. These segments provide more water molecules in the environment of the ester groups, accelerating the degradation reaction and thus increasing the biodegradability [38].

(a)

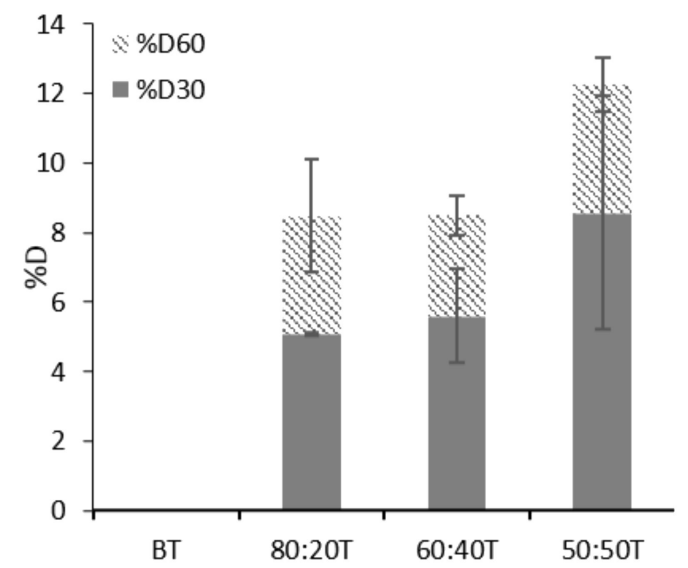

(b)

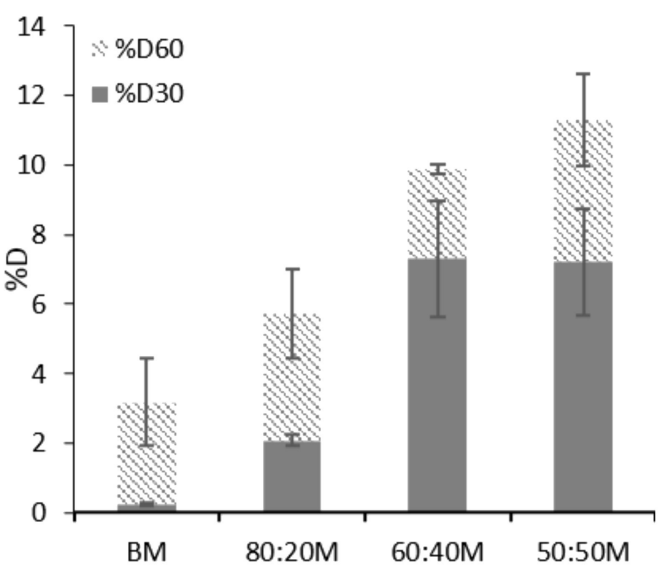

Figure 7. Percentage of biodegradability of (a) TDI LWS-PU foams and (b) MDI LWS-PU foams after 30 days $\left(\% D_{30}\right)$ and 60 days $\left(\% D_{60}\right)$.

\section{Conclusions}

Wheat straw residues were used to produce a natural bio-polyol by means of a highly optimized liquefaction procedure, which reported an excellent yield (96.5\%). This polyol exhibited excellent properties for the preparation of flexible polyurethane foams $\left(\mathrm{I}_{\mathrm{OH}} 604.1 \mathrm{mg} \mathrm{KOH} / \mathrm{g}\right.$ and viscosity $0.6 \mathrm{~Pa} \cdot \mathrm{s}$ ) where a vegetable oil such as castor oil was substituted by the liquefied product up to $50 \% w t$. Additionally, the as-mentioned polyurethane foams were prepared using two different isocyanates (MDI and TDI) studying their influence in the final polymer structure.

Foams prepared with both TDI and MDI achieved their optical physical and mechanical properties with $40 \%$ bio-polyol substitution (specific compressive strengths of 0.390 and $0.108 \mathrm{KPa} \cdot \mathrm{m}^{3} / \mathrm{Kg}$, and Young's moduli of 5.583 and $1.719 \mathrm{KPa} \cdot \mathrm{m}^{3} / \mathrm{Kg}$ for TDI and MDI foams, respectively). These same foams presented an orderly and compact cell structure as well as improved thermal characters.

Finally, biodegradability assays showed that by increasing the amount of wheat straw polyol in the polymer foams, the biodegradability was also improved after 30 and 60 days. Furthermore, this property was increased up to $40 \%$ of polyol substitution in the system, being maintained with higher quantities. In this way, results obtained through this study encourage the use of wheat straw polyol as an efficient substituent for castor oil in polyurethane foams, which can be used in plant nurseries.

Supplementary Materials: The following are available online at http://www.mdpi.com/2073-4360/12/11/2646/s1, Table S1: Apparent density and mechanical properties of LWS-PU-foams, Table S2: Thermal characters and biodegradability of LWS-formulated foams.

Author Contributions: Conceptualization, L.S. and R.B.; methodology, L.S. and A.G.; investigation, L.S. and A.G.; writing-original draft preparation, L.S., E.R., J.R., and R.B.; writing-review and editing, L.S., E.R., J.R., and R.B.; supervision, L.S., A.G., and R.B.; project administration, R.B.; funding acquisition, R.B. All authors have read and agreed to the published version of the manuscript.

Funding: This research was funded by the Spanish Ministry of Economy, Industry and Competitiveness (Ramon y Cajal contract ref. RYC-2015-17109). R. Briones thanks the Chilean National Commission for Scientific and 
Technological Research (CONICYT Fondecyt Iniciación/cod.11160914; CONICYT Programa de Cooperación Internacional/REDES180165) for supporting this research.

Conflicts of Interest: The authors declare no conflict of interest.

\section{References}

1. Lozano, F.J.; Lozano, R. Assessing the potential sustainability benefits of agricultural residues: Biomass conversion to syngas for energy generation or to chemicals production. J. Clean. Prod. 2018, 172, 4162-4169. [CrossRef]

2. Food and Agriculture Organization Corporate Statistical Database (FAOSTAT). New Food Balances. Available online: http://www.fao.org/faostat/en/\#data/FBS (accessed on 2 December 2019).

3. Saini, J.K.; Saini, R.; Tewari, L. Lignocellulosic agriculture wastes as biomass feedstocks for second-generation bioethanol production: Concepts and recent developments. 3 Biotech. 2015, 5, 337-353. [CrossRef] [PubMed]

4. Espinosa, E.; Tarrés, Q.; Delgado-Aguilar, M.; González, I.; Mutjé, P.; Rodríguez, A.; Espinosa, E.; Rodríguez, A. Suitability of wheat straw semichemical pulp for the fabrication of lignocellulosic nanofibres and their application to papermaking slurries. Cellulose 2015, 23, 837-852. [CrossRef]

5. Tomás-Pejó, E.; Fermoso, J.; Herrador, E.; Hernando, H.; Jiménez-Sánchez, S.; Ballesteros, M.; González-Fernández, C.; Serrano, D. Valorization of steam-exploded wheat straw through a biorefinery approach: Bioethanol and bio-oil co-production. Fuel 2017, 199, 403-412. [CrossRef]

6. Yang, S.; Bai, S.; Wang, Q. Sustainable packaging biocomposites from polylactic acid and wheat straw: Enhanced physical performance by solid state shear milling process. Compos. Sci. Technol. 2018, 158, $34-42$. [CrossRef]

7. Espinosa, E.; Bascón-Villegas, I.; Rosal, A.; Pérez-Rodríguez, F.; Chinga-Carrasco, G.; Rodríguez, A. PVA/(ligno)nanocellulose biocomposite films. Effect of residual lignin content on structural, mechanical, barrier and antioxidant properties. Int. J. Biol. Macromol. 2019, 141, 197-206. [CrossRef] [PubMed]

8. Domínguez-Robles, J.; Sánchez, R.; Díaz-Carrasco, P.; Espinosa, E.; García-Domínguez, M.; Rodríguez, A. Isolation and characterization of lignins from wheat straw: Application as binder in lithium batteries. Int. J. Biol. Macromol. 2017, 104, 909-918. [CrossRef]

9. Ruiz, H.A.; Cerqueira, M.A.; Silva, H.D.; Rodríguez-Jasso, R.M.; Vicente, A.A.; Teixeira, J.A. Biorefinery valorization of autohydrolysis wheat straw hemicellulose to be applied in a polymer-blend film. Carbohydr. Polym. 2013, 92, 2154-2162. [CrossRef]

10. Behrendt, F.; Neubauer, Y.; Oevermann, M.; Wilmes, B.; Zobel, N. Direct Liquefaction of Biomass. Chem. Eng. Technol. 2008, 31, 667-677. [CrossRef]

11. Jiang, W.; Kumar, A.; Adamopoulos, S. Liquefaction of lignocellulosic materials and its applications in wood adhesives-A review. Ind. Crop. Prod. 2018, 124, 325-342. [CrossRef]

12. Gómez-Jiménez-Aberasturi, O.; Ochoa-Gómez, J.R. New approaches to producing polyols from biomass. J. Chem. Technol. Biotechnol. 2017, 92, 705-711. [CrossRef]

13. Tanaka, R.; Hirose, S.; Hatakeyama, H. Preparation and characterization of polyurethane foams using a palm oil-based polyol. Bioresour. Technol. 2008, 99, 3810-3816. [CrossRef] [PubMed]

14. Bernardini, J.; Cinelli, P.; Anguillesi, I.; Coltelli, M.-B.; Lazzeri, A. Flexible polyurethane foams green production employing lignin or oxypropylated lignin. Eur. Polym. J. 2015, 64, 147-156. [CrossRef]

15. Zhang, L.; Zhang, M.; Hu, L.; Zhou, Y. Synthesis of rigid polyurethane foams with castor oil-based flame retardant polyols. Ind. Crop. Prod. 2014, 52, 380-388. [CrossRef]

16. Trevino, A.; Trumbo, D. Acetoacetylated castor oil in coatings applications. Prog. Org. Coatings 2002, 44, 49-54. [CrossRef]

17. Technical Association of the Pulp and Paper Industry (TAPPI). TAPPI Standards: Regulation and Style Guidelines. Revised January 2018. Available online: http://www.tappi.org/content/pdf/standards/tm_ guidelines_complete.pdf (accessed on 10 November 2020).

18. Briones, R.; Serrano, L.; Labidi, J. Valorization of some lignocellulosic agro-industrial residues to obtain biopolyols. J. Chem. Technol. Biotechnol. 2011, 87, 244-249. [CrossRef]

19. Briones, R.; Serrano, L.; Llano-Ponte, R.; Labidi, J. Polyols obtained from solvolysis liquefaction of biodiesel production solid residues. Chem. Eng. J. 2011, 175, 169-175. [CrossRef] 
20. Li, H.; Feng, S.; Yuan, Z.; Wei, Q.; Souzanchi, S. Highly efficient liquefaction of wheat straw for the production of bio-polyols and bio-based polyurethane foams. Ind. Crop. Prod. 2017, 109, 426-433. [CrossRef]

21. Kim, D.-H.; Kwon, O.-J.; Yang, S.-R.; Park, J.; Chun, B.C. Structural, thermal, and mechanical properties of polyurethane foams prepared with starch as the main component of polyols. Fibers Polym. 2007, 8, 155-162. [CrossRef]

22. Rincón, E.; Balu, A.M.; Luque, R.; Serrano, L. Insulating rigid polyurethane foams from laurel tree pruning based polyol. J. Appl. Polym. Sci. 2020, 138, 49789. [CrossRef]

23. ASTM D4274-16, Standard Test Method for Testing Polyurethane Raw Materials: Determination of Hydroxyl Numbers of Polyols; ASTM International: West Conshohocken, PA, USA, 2016.

24. ASTM D1622/D1622M-14, Standard Method For Apparent Density of Rigid Cellular Plastics; ASTM International: West Conshohocken, PA, USA, 2008.

25. ASTM D1621-16, Standard Test Method for Compressive Properties of rigid Cellular Plastics; ASTM International: West Conshohocken, PA, USA, 2016.

26. Huang, G.; Wang, P. Effects of preparation conditions on properties of rigid polyurethane foam composites based on liquefied bagasse and jute fibre. Polym. Test. 2017, 60, 266-273. [CrossRef]

27. ASTM D5988-03, Standard Test Method for Determining Aerobic Biodegradation in Soil of Plastic Materials or Residual Plastic Materials After Composting; ASTM International: West Conshohocken, PA, USA, 2003.

28. Kurańska, M.; Prociak, A. The influence of rapeseed oil-based polyols on the foaming process of rigid polyurethane foams. Ind. Crop. Prod. 2016, 89, 182-187. [CrossRef]

29. Zlatanić, A.; Lava, C.; Zhang, W.; Petrović, Z.S. Effect of structure on properties of polyols and polyurethanes based on different vegetable oils. J. Polym. Sci. Part. B Polym. Phys. 2004, 42, 809-819. [CrossRef]

30. Zhang, J.; Hori, N.; Takemura, A. Influence of NCO/OH ratio on preparation of four agricultural wastes liquefied polyols based polyurethane foams. Polym. Degrad. Stab. 2020, 179, 109256. [CrossRef]

31. Kirpluks, M.; Kalnbunde, D.; Benes, H.; Cabulis, U. Natural oil based highly functional polyols as feedstock for rigid polyurethane foam thermal insulation. Ind. Crop. Prod. 2018, 122, 627-636. [CrossRef]

32. Cinelli, P.; Anguillesi, I.; Lazzeri, A. Green synthesis of flexible polyurethane foams from liquefied lignin. Eur. Polym. J. 2013, 49, 1174-1184. [CrossRef]

33. Wang, C.; Zheng, Y.; Xie, Y.; Qiao, K.; Sun, Y.; Yue, L. Synthesis of bio-castor oil polyurethane flexible foams and the influence of biotic component on their performance. J. Polym. Res. 2015, 22, 1-9. [CrossRef]

34. Tu, Y.-C.; Suppes, G.J.; Hsieh, F.-H. Water-blown rigid and flexible polyurethane foams containing epoxidized soybean oil triglycerides. J. Appl. Polym. Sci. 2008, 109, 537-544. [CrossRef]

35. Mosiewicki, M.; Dell'Arciprete, G.; Aranguren, M.; Marcovich, N. Polyurethane Foams Obtained from Castor Oil-based Polyol and Filled with Wood Flour. J. Compos. Mater. 2009, 43, 3057-3072. [CrossRef]

36. Hejna, A.; Kirpluks, M.; Kosmela, P.; Cabulis, U.; Haponiuk, J.; Łukasz, P. The influence of crude glycerol and castor oil-based polyol on the structure and performance of rigid polyurethane-polyisocyanurate foams. Ind. Crop. Prod. 2017, 95, 113-125. [CrossRef]

37. Wang, H.J.; Rong, M.Z.; Zhang, M.Q.; Hu, J.; Chen, H.W.; Czigány, T. Biodegradable Foam Plastics Based on Castor Oil. Biomacromolecules 2008, 9, 615-623. [CrossRef] [PubMed]

38. Yeganeh, H.; Hojati-Talemi, P. Preparation and properties of novel biodegradable polyurethane networks based on castor oil and poly(ethylene glycol). Polym. Degrad. Stab. 2007, 92, 480-489. [CrossRef]

Publisher's Note: MDPI stays neutral with regard to jurisdictional claims in published maps and institutional affiliations.

(C) 2020 by the authors. Licensee MDPI, Basel, Switzerland. This article is an open access article distributed under the terms and conditions of the Creative Commons Attribution (CC BY) license (http://creativecommons.org/licenses/by/4.0/). 